\title{
Dinámica poblacional de los estadios inmaduros del vector del dengue Aedes aegypti (Diptera: Culicidae): un estudio longitudinal (1996-2000)
}

\author{
María V. Micieli, Juan J. García, María F. Achinelly \& Gerardo A. Martí \\ Centro de Estudios Parasitológicos y de Vectores, CEPAVE (UNLP-CONICET), Calle 2, No 584, (1900) La Plata, \\ Argentina. Fax: (54) 221-4232327; cepave@cepave.edu.ar
}

Recibido 20-II-2002. Corregido 19-XI-2003. Aceptado 25-II-2004.

\begin{abstract}
Population dynamics of the immature stages of Aedes aegypti (Diptera: Culicidae), vector of dengue: a longitudinal study (1996-2000). A four year study was conducted on a natural population of immature stages of Aedes aegypti after the re-invasion of Argentina by this vector in 1987. Thirty six plastic containers with $700 \mathrm{ml}$ of dechlorinated water were placed in the La Plata Zoological Garden, La Plata, Argentina. A strip of filter paper around each container was added to facilitate egg counting. Eggs, larvae and pupae were counted weekly in each container from September, 1996 to August, 2000. After egg counting, papers were submerged to facilitate egg hatching and a new paper was placed in each container. Presence of A. aegypti immature stages was recorded from December-January to June during each of the four years of this study. In 1997, 13105 eggs, 7978 larvae and 1476 pupae were registered with $54.7 \%$ positive containers; during 1998, 8194 eggs, 668 larvae and 142 pupae were recorded with $28.3 \%$ positive containers; 13510 eggs, 3690 larvae and 743 pupae were registered during 1999 with $56.7 \%$ positive containers; and 16327 eggs, 4669 larvae and 715 pupae during 2000 with $59.3 \%$ of containers with presence of $A$. aegypti. Egg number and hatching rate were drastically reduced in 1998 when temperatures from December to May were 1 to $2.5{ }^{\circ} \mathrm{C}$ lower than the other years of this study. These colder than usual temperatures in the summer of 1998 were a consequence of the El Niño event. Rev. Biol. Trop. 54 (3): 979-983. Epub 2006 Sept. 29.
\end{abstract}

Key words: Aedes aegypti, immature population dynamics, climatic change, ovitraps, Argentina.

Aedes aegypti L. es el vector principal del virus de dengue en las Américas. El Ministerio de Asistencia Social y Salud Pública de la Argentina y la Oficina Sanitaria Panamericana declararon la erradicación de A. aegypti en la Argentina en 1965 (Carcavallo y Martinez 1968). En 1987 se produjo la reinvasión de la Argentina por el vector, citándoselo para las provincias del noreste, Formosa y Misiones (Anónimo 1990). Posteriores citas ampliaron la distribución del vector a la provincia de Buenos Aires (Campos 1993), en el este y a la provincia de Córdoba, en el centro de la Argentina (Almirón y Ludueña Almeida 1998). Luego de 14 años de producida la reinfestación de la Argentina por A. aegypti y con una distribución que actualmente abarca a 12 provincias, la información publicada sobre la biología y ecología del vector, es escasa y limitada a dos estudios realizados en poblaciones de $A$. aegypti en Buenos Aires (Campos y Maciá 1996) y Córdoba (Dominguez et al. 2000) durante una temporada. La ciudad de La Plata constituye el límite sur de la distribución de $A$. aegypti en la Argentina (García et al. 2002). Durante cuatro años se estudió la variación estacional de una población de estadios inmaduros de $A$. aegypti en La Plata obteniéndose información sobre la dinámica de los mismos y el efecto de la temperatura sobre la actividad del vector, incluyendo los posibles efectos del fenómeno climático conocido como corriente El Niño. 


\section{MATERIALES Y MÉTODOS}

El área de estudio se ubicó en el Jardín Zoológico de la ciudad de La Plata, provincia de Buenos Aires, Argentina. En septiembre de 1996 se colocaron 36 recipientes plásticos de $1000 \mathrm{ml}$ pintados de color negro. En cada recipiente se agregaron $700 \mathrm{ml}$ de agua libre de cloro y una tira de papel de filtro de $30 \times 6 \mathrm{~cm}$ rodeando el perímetro interno, como substrato para la colocación de los huevos. A partir de septiembre de 1996 y hasta agosto de 2000 se examinaron los recipientes semanalmente para detectar la presencia de A. aegypti. En cada oportunidad se retiraron los papeles y se cuantificaron los huevos. El contenido de cada recipiente fue colocado en una bandeja blanca, se cuantificaron las larvas y pupas de $A$. aegypti y se registró la presencia de otras especies de culícidos. El agua y los estados inmaduros fueron retornados a los recipientes, se sumergieron los papeles para facilitar la eclosión de los huevos y se colocó una tira nueva de papel en cada recipiente. Se agregó semanalmente agua a los recipientes hasta completar el volumen inicial $(700 \mathrm{ml})$. Durante el verano de 1998 y comienzo de la temporada 1999 se observó una marcada reducción del número de larvas en relación a los huevos censados. Para determinar la viabilidad de esos huevos, semanalmente se obtuvieron trozos pequeños de papeles con huevos, se llevaron al laboratorio y se inundaron en bandejas con agua sin cloro a $26^{\circ} \mathrm{C}$.

Los datos de las temperaturas máximas, medias y mínimas diarias fueron suministrados por el Servicio Meteorológico de la Universidad Nacional de La Plata, La Plata, Argentina.

\section{RESULTADOS}

Temporada 1997: Los estados inmaduros de $A$. aegypti se observaron de enero a julio de 1997. Durante este período se censaron 13 105 huevos, 7978 larvas y 1476 pupas con un promedio de 13.2 huevos, 8 larvas y 1.5 pupas por recipiente (Fig. 1). Las oviposiciones se extendieron hasta mayo, mes durante el cual se registraron temperaturas medias de $15.2{ }^{\circ} \mathrm{C}$. Los números máximos de huevos se registraron en marzo $(\mathrm{n}=4384)$ y abril $(\mathrm{n}=4764)$ (Fig. 1). El $60.6 \%$ de los huevos colocados en esta temporada eclosionó, mientras el $11.3 \%$ llegó al estado pupa, siendo el promedio de recipientes positivos $54.7 \%$. Las temperaturas máximas, medias y mínimas desde diciembre de 1996 hasta mayo de 1997 fueron: $26.4{ }^{\circ} \mathrm{C}, 20.5{ }^{\circ} \mathrm{C}$ y $15.6{ }^{\circ} \mathrm{C}$ (Fig. 1). Desde junio a noviembre de 1997 no se registraron nuevas oviposiciones.

Temporada 1998: A partir de diciembre y hasta mayo de 1998 se censaron 8194 huevos, 668 larvas y 142 pupas, cantidades marcadamente inferiores a las registradas en 1997, 1999 y 2000 . El promedio por recipiente fue 9.1 huevos, 0.74 larvas y 0.15 pupas (Fig. 1). La eclosión de los huevos también presentó una reducción sensible siendo de $8.1 \%$ del total de huevos censados en la temporada y solamente el $1.7 \%$ de esos huevos llegó al estado pupa. Las muestras de estos huevos inundados en el laboratorio a $26{ }^{\circ} \mathrm{C}$ eclosionaron entre 80 y $90 \%$. El número máximo de huevos $(\mathrm{n}=3604)$ se censó en marzo, mientras las oviposiciones nuevas se detectaron hasta mayo de 1998, con temperaturas medias de $14.3^{\circ} \mathrm{C}$ (Fig. 1). El promedio de recipientes con $A$. aegypti en 1998 fue $28.3 \%$, aproximadamente la mitad del correspondiente a la temporada anterior. Las temperaturas máximas, medias y mínimas de diciembre de 1997 a mayo de 1998 fueron $23.8{ }^{\circ} \mathrm{C}, 18.8{ }^{\circ} \mathrm{C}$ y $14.6{ }^{\circ} \mathrm{C}$, coincidiendo esta temporada con el fenómeno global denominado corriente El Niño. Desde junio a diciembre de 1998 no se registraron oviposiciones nuevas.

Temporada 1999: Los estados inmaduros de A. aegypti se registraron de enero a junio de 1999. En este período se censaron 13150 huevos, 3690 larvas y 743 pupas. El promedio de huevos, larvas y pupas por recipiente fue 15 , 4.1 y 0.8 respectivamente (Fig. 1). El porcentaje de eclosión de los huevos censados ascendió a $27.3 \%$ y el $5.3 \%$ de estos huevos llegó a pupa. Durante marzo se registró el número máximo de huevos de los cuatro años ( $\mathrm{n}=9$ 959); ovipo- 

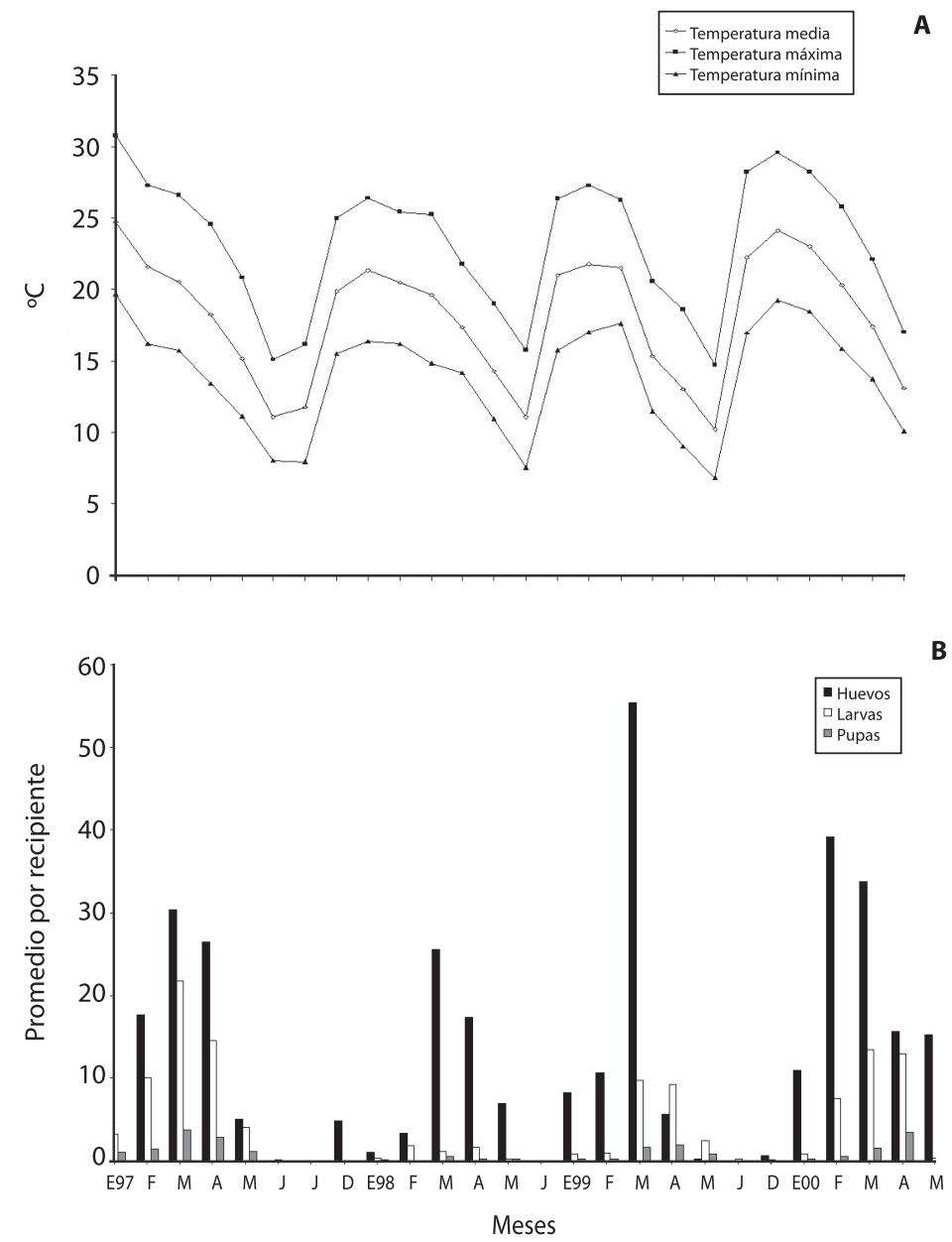

Fig. 1. A. Temperaturas máximas, mínimas y medias (promedio mensual) durante el período de estudio. B. Número promedio por recipiente de huevos, larvas y pupas de Aedes aegypti.

Fig. 1. A. Maximun, minimun and mean temperatures (month average) during the study. B. Average number of eggs, larvae and pupa of Aedes aegypti per container.

siciones nuevas se registraron hasta mayo con temperaturas medias de $13.1{ }^{\circ} \mathrm{C}$. El promedio de recipientes con $A$. aegypti fue $56.7 \%$. Las temperaturas máximas, medias y mínimas de diciembre de 1998 hasta mayo de 1999 fueron $24.4{ }^{\circ} \mathrm{C}, 18.9^{\circ} \mathrm{C}$ y $14.4{ }^{\circ} \mathrm{C}$ (Fig. 1). Desde julio a noviembre de 1999 no se observaron estados inmaduros de $A$. aegypti.

Temporada 2000: En diciembre se registraron las primeras oviposiciones de esta temporada las que se prolongaron hasta mayo de
2000 con una temperatura media de $13.1{ }^{\circ} \mathrm{C}$. Los números máximos de huevos censados se registraron en febrero $(n=7048)$ y marzo $(n=$ 3 990). Durante esta temporada se censaron 16 327 huevos, 4669 larvas y 715 pupas, con un promedio por recipiente de 20.8 huevos, 5.9 larvas y 0.9 pupas y $59.3 \%$ de recipientes positivos (Fig. 1). La eclosión de los huevos censados fue $28.3 \%$ y $4.3 \%$ llegó a pupa. Las temperaturas promedio máximas, medias y mínimas registradas en esta temporada fueron $25.2{ }^{\circ} \mathrm{C}, 20.1{ }^{\circ} \mathrm{C}$ y $15.8^{\circ} \mathrm{C}$ respectivamente (Fig. 1). 
Culex pipiens $\mathrm{L}$. fue la única especie de culícido que cohabitó con A. aegypti durante las cuatro temporadas de estudio. El porcentaje de recipientes con presencia de $C x$. pipiens fue de $73.4 \%$ en 1997, $64.7 \%$ en $1998,87.8 \%$ en 1999 y $84 \%$ en 2000 durante el período en que estuvo $A$. aegypti presente. Los estados inmaduros de Cx. pipiens estuvieron presentes en los 36 recipientes censados durante todo el estudio, experimentando reducciones durante los meses invernales, inclusive desapariciones esporádicas.

\section{DISCUSIÓN}

La duración de la actividad estacional de A. aegypti en la Argentina, determinada por el registro de oviposiciones nuevas, varió con la latitud. Micieli y Campos (2003) determinaron que las poblaciones de A. aegypti en Tartagal, provincia de Salta, en el norte de la Argentina $\left(22^{\circ} 32^{\prime} \mathrm{S}, 63^{\circ} 49^{\prime} \mathrm{W}\right)$, se mantuvieron activas durante todo el año, con excepción de los meses de junio y julio. La actividad de este vector se redujo al período octubre-mayo en la ciudad de Córdoba $\left(31^{\circ} 25^{\prime} \mathrm{S}, 64^{\circ} 11^{\prime} \mathrm{W}\right)$, centro de la Argentina (Domínguez et al. 2000). En el presente trabajo se determinó que $A$. aegypti mantuvo la actividad en el límite meridional de su distribución en la Argentina (34 $55^{\circ}$ S, $57^{\circ} 57^{\prime} \mathrm{W}$ ) de diciembre-enero hasta mayo.

El umbral térmico por debajo del cuál cesan las oviposiciones de las hembras de $A$. aegypti fue determinado en $17{ }^{\circ} \mathrm{C}$ para poblaciones de la provincia de Córdoba (Domínguez et al. 2000) y de Quilmes, provincia de Buenos Aires (Campos y Maciá 1996). El presente trabajo, determinó que la actividad de $A$. aegypti continuó con temperaturas medias entre $13{ }^{\circ} \mathrm{C}$ y $15^{\circ} \mathrm{C}$ durante los cuatro años de este estudio.

En la temporada 1998 y comienzo de 1999, se produjo un descenso marcado del número y eclosión de los huevos colocados en los recipientes. La viabilidad de estos huevos fue confirmada en el laboratorio, obteniéndose porcentajes de eclosión superiores a $80 \%$ a $26^{\circ} \mathrm{C}$. Durante esas dos temporadas se registraron temperaturas mínimas, medias y máximas de diciembre a mayo inferiores entre $1{ }^{\circ} \mathrm{C}$ y $2.5^{\circ} \mathrm{C}$ respecto del mismo período en las temporadas 1997 y 2000 . Estas temperaturas inferiores registradas en el verano de 1998 e inicio de 1999 fueron una consecuencia del fenómeno climático global denominado "corriente del Niño", y que especulamos fue responsable de la marcada reducción de la eclosión de los huevos de A. aegypti. Esta drástica reducción poblacional también se observó en 1998 en una población del vector localizada en el cementerio municipal de La Plata (García et al. 2002). En esa ocasión se detectó la presencia de A. aegypti a partir de marzo de 1998 y en solo seis muestreos semanales durante el período diciembre de 1997 a junio de 1998. El porcentaje máximo de recipientes positivos registrado en ese estudio fue $0.4 \%$ en abril de 1998 con un promedio de 2.5 larvas y pupas por recipientes.

Rodhain y Rosen (1997) concluyen que los principales factores que regulan las poblaciones de $A$. aegypti en las ciudades son las condiciones climáticas y la disponibilidad de recipientes artificiales. En este trabajo se demostró la estrecha relación de la temperatura con la actividad de $A$. aegypti, así como también la disponibilidad de recipientes artificiales determinó la densidad de los estados inmaduros del vector y probablemente determinó el tamaño de la población. Campos y Maciá (1996) utilizaron nueve recipientes artificiales en los que registraron $100 \%$ de recipientes positivos, con 63 huevos y 60 larvas por recipiente/ semana. García et al. (2002) muestrearon 320 recipientes semanales, sobre un total estimado de 120000 recipientes, en el cementerio de La Plata durante la temporada 1996/97, registrando valores máximos de $3.5 \%$ de recipientes positivos y 10 larvas y pupas por recipiente. En el presente trabajo en el que se censaron 36 recipientes semanales, los recipientes positivos no superaron el $60 \%$ en los cuatro años, siendo el promedio máximo de estados inmaduros por recipiente, 20.8 huevos, 8 larvas y 1.5 pupas.

Los estudios sobre la biología y ecología de A. aegypti en la Argentina deben incrementarse 
a fin de optimizar los resultados de los programas de control de este vector.

\section{AGRADECIMIENTOS}

Agradecemos a las autoridades y al personal del Jardín Zoológico de la ciudad de La Plata por su valiosa colaboración para el desarrollo de este trabajo. María V. Micieli, es Investigadora del CONICET y Juan J. García es Investigador del CIC.

\section{RESUMEN}

Se realizó un estudio de la variación estacional de una población de estadios inmaduros de A. aegypti en La Plata, Argentina, durante cuatro años. Se colocaron 36 recipientes plásticos con $700 \mathrm{ml}$ de agua declorinada y se agregó, en cada uno, una tira de papel de filtro rodeando el perímetro interno como sitio para la ovipostura. Los huevos, larvas y pupas se cuantificaron semanalmente desde septiembre de 1996 hasta agosto de 2000. Tras cuantificar el número de huevos, los papeles fueron sumergidos en cada recipiente para facilitar la eclosión y se agregó un nuevo papel. La presencia de estados inmaduros de $A$. aegypti fue registrada desde diciembre-enero hasta junio durante los cuatro años de estudio. En 1997 se registraron 13105 huevos, 7978 larvas y 1476 pupas con un $54.7 \%$ de recipientes positivos; en 1998, 8194 huevos, 668 larvas y 142 pupas y un $28.3 \%$ de recipientes positivos para este mosquito. En 1999 se obtuvieron 13510 huevos, 3690 larvas y 743 pupas y un $56.7 \%$ de recipientes con $A$. aegypti. Para el año 2000 se registraron 16327 huevos, 4669 larvas y 715 pupas y un porcentaje de recipientes positivos de $59.3 \%$. El número de huevos y el porcentaje de eclosión se redujo drásticamente en 1998 donde las temperaturas durante el período diciembre-mayo fueron entre uno y $2.5^{\circ} \mathrm{C}$ más bajas que durante los otros tres años de estudio. Estas temperaturas menores fueron consecuencia del fenómeno climático corriente El Niño.
Palabras clave: Aedes aegypti, dinámica de poblaciones inmaduras, cambio climático, Argentina.

\section{REFERENCIAS}

Anónimo. 1990. Las condiciones de la salud en las Américas. O.M.S. 1: 152-174.

Almirón, W.R. \& F. Ludueña Almeida. 1998. Aedes aegypti (Diptera: Culicidae) en Córdoba, Argentina. Rev. Soc. Entomol. Argent. 57: 27-28.

Campos, R.E. \& A. Maciá. 1996. Observaciones biológicas de una población natural de Aedes aegypti (Diptera: Culicidae) en la provincia de Buenos Aires, Argentina. Rev. Soc. Entomol. Argent. 55: 67-72.

Carcavallo, R.U. \& A. Martínez. 1968. Entomoepidemiología de la República Argentina. Capítulo III. Fiebre amarilla, vectores y cadena epidemiológica. Comun. Cient. Jta. Invest. Cient. Fuerzas Arm. Argent. 13: 105-144.

Domínguez, M.C., F.F. Ludueña Almeida \& W.R. Almirón. 2000. Dinámica poblacional de Aedes aegypti (Diptera: Culicidae) en Córdoba capital. Rev. Soc. Entomol. Argent. 59: 41-50.

García, J.J., M.V. Micieli, M.F. Achinelly \& G.A. Marti. 2002. Establecimiento de una población de Aedes aegypti L. en La Plata, Argentina. Actualizaciones en artropodología sanitaria argentina. Serie: Enfermedades Transmisibles, RAVE, Comp. D.O.Salomón. Publ. Monogr. 2: 149-153.

Micieli, M.V. \& R.E. Campos. 2003. Monthly oviposition activity and seasonal pattern of Aedes (St.) aegypti (L.) (Diptera: Culicidae) population at subtropical Argentina. Mem. Inst. Oswaldo Cruz 98: 659-663.

Rodhain, F. \& L. Rosen. 1997. Mosquito vectors and dengue virus-vector relationships, p. 45-61. In D.J.Gubler $\&$ G. Kuno (eds.). Dengue and dengue hemorrhagic fever. Cambridge University, Cambridge, Inglaterra. 
